\title{
Exogeoconservation: Protecting geological heritage on celestial bodies
}

\author{
Jack J. Matthews ${ }^{\mathrm{a}, \mathrm{b}}$, *, Sean McMahon ${ }^{\mathrm{c}}$ \\ a Department of Earth Sciences, Memorial University of Newfoundland, St John's, Newfoundland, Canada \\ b Oxford University Museum of Natural History, Parks Road, Oxford, UK \\ ${ }^{c}$ UK Centre for Astrobiology, School of Physics and Astronomy, University of Edinburgh, UK
}

Geoconservation is an increasingly widely adopted theoretical, practical and administrative approach to the protection of geological and geomorphological features of special scientific, functional, historic, cultural, aesthetic, or ecological value. Protected sites on Earth include natural rocky outcrops, shorelines, river banks, and landscapes, as well as human-made structures such as road cuts and quarries exposing geological phenomena. However, geoconservation has rarely been discussed in the context of other rocky and icy planets, rings, moons, dwarf planets, asteroids, or comets, which present extraordinarily diverse, beautiful, and culturally, historically and scientifically important geological phenomena. Here we propose to adapt geoconservation strategies for protecting the geological heritage of these celestial bodies, and introduce the term 'exogeoconservation' and other associated terms for this purpose. We argue that exogeoconservation is acutely necessary for the scientific exploration and responsible stewardship of celestial bodies, and suggest how this might be achieved and managed by means of international protocols. We stress that such protocols must be sensitive to the needs of scientific, industrial, and other human activities, and not unduly prohibitive. However, with space exploration and exploitation likely to accelerate in coming decades, it is increasingly important that an internationally agreed, holistic framework be developed for the protection of our common 'exogeoheritage'.

\section{Introduction}

In recent decades, planetary science missions have revealed a wealth of geological diversity on the rocky inner planets, the icy and rocky moons of the gas giants, the dwarf planets of the outer solar system, and many comets and asteroids. The anticipated growth of off-world human activity in coming years demands that a concerted and coherent intellectual, practical, and ultimately legal effort be made to protect these extraterrestrial objects against new anthropogenic threats to their most valuable features [1]. The dominance of biological and ecological narratives around conservation on Earth may partially explain why conservation strategies for (presumed) sterile extraterrestrial environments have yet to advance much beyond the preliminary staking-out of positions. These include the proposal for "planetary parks" on Mars outlined by Cockell and Horneck [2], and various schemes to protect the archeology of space exploration $[3,4]$, mitigate the risk of biological contamination [5], minimize the dangers of spacecraft debris [6], and prevent the scarring of celestial bodies by mining [7].
Conservation on Earth has mainly focused on the biosphere, with lesser efforts directed towards the atmosphere, hydrosphere, and geosphere. However, celestial bodies lack known life, commonly have negligible atmospheres, and rarely sustain large bodies of liquid at the surface, the organic lakes of Titan being an interesting exception (Fig. 1). Thus, the geosphere (rocky or icy matter) of a celestial body is usually the feature on which human interests and activities most seriously seriously impinge. The appropriate existing conservation approach is therefore geoconservation, which may be defined as the identification and protection of geological and geomorphological features of special scientific, functional, historic, cultural, aesthetic, or ecological value [8-10]. Such features include natural rocky outcrops, shorelines, river banks, and landscapes, as well as human-made structures such as road cuts and quarries. The principles and practices of geoconservation have now been developing for well over 100 years, with early examples of protected geological sites ("geosites") including Yellowstone National Park, USA (1872) and the Agassiz Rock in Edinburgh, Scotland (1908). A wide range of formal designations are now applied to geosites by scientific, local, regional, national, and international communities, confer-

\footnotetext{
* Corresponding author. Memorial University of Newfoundland, St John's, Newfoundland, Canada.

Email address: jjmatthews@mun.ca (Jack.J. Matthews)
} 

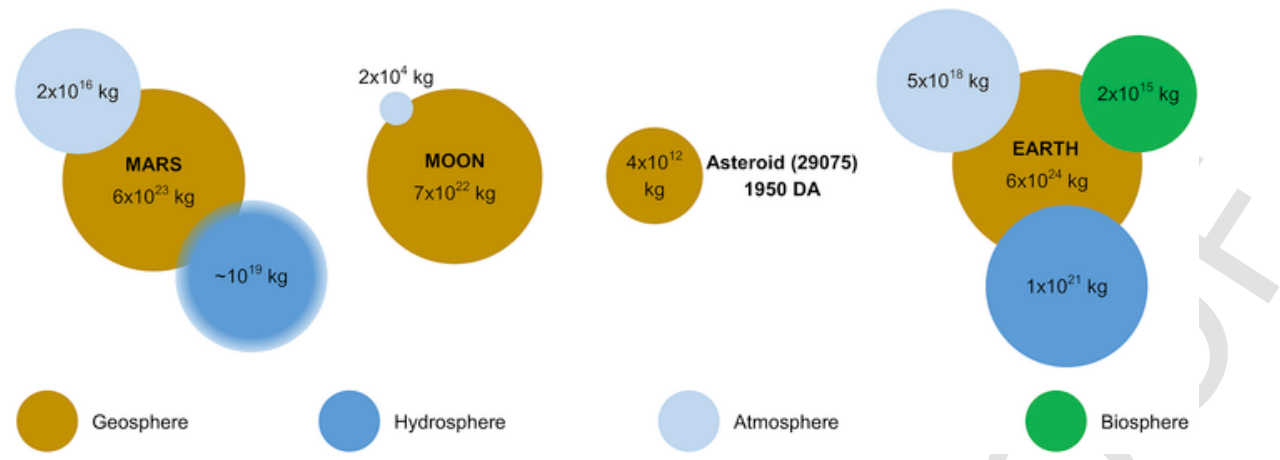

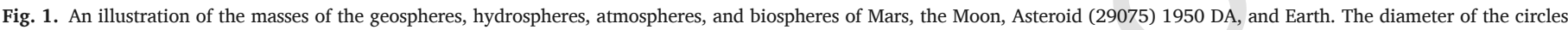
is logarithmically proportional to mass [30-33].

ring a variety of special protections. However, although mentioned in passing by Cockell and Horneck [2], it has not yet been widely realized that existing geoconservation theory and practice provide a ready-made paradigm for understanding why, where, and how the protection of lifeless arrangements of matter may be achieved beyond Earth.

The implementation and popular awareness of geoconservation on Earth lags behind biological conservation, and many countries are still developing legislative frameworks to safeguard important geological and geomorphological sites. Nevertheless, a great deal of groundwork has been done, especially on protecting sites of scientific value, i.e., those where exemplary or exceptional structural, lithological, mineralogical, volcanic, palaeontological and stratigraphic phenomena can be observed. Innumerable sites like these have been more or less formally described as "type localities", while layered outcrops with similar importance are designated "stratotypes" (see the International Stratigraphic Guide [11]); stratotypes have been established at the boundaries of many important subdivisions of geological time. The use of such a designation does not necessarily imply that geoconservation measures are in force, but to be useful to the scientific community in the long term, these sites must be-and increasingly commonly are-placed under special protection. Minimally, geoconservation seeks to manage these features so that their value is maintained, and not necessarily either to freeze them in time or to minimize all human intervention; the aim is thus conservation, not necessarily preservation. This constraint may also apply to extraterrestrial sites where intervention to prevent natural processes of alteration would be prohibitively expensive or impractical.

\section{A new term: "exogeoconservation"}

The field of 'planetary protection' is traditionally concerned with mitigating biological cross-contamination of planetary bodies, but could be expanded to include other forms of conservation. However, recognising the dominance of geological features amongst those objects to be conserved, we propose a new term, 'exogeoconservation', to represent the extension of geoconservation principles and activities to rocky/ icy matter in outer space, including celestial bodies. This term clearly signifies an extension of the existing geoconservation framework, and should be used regardless of whether exogeoconservation is considered a part of 'planetary protection' or not. Specifically, we define exogeoconservation as: the identification of scientific, historic, aesthetic, ecological or cultural value in celestial bodies and in their component geological and geomorphological features, and the protection of such bodies and features. Those bodies and features deemed valuable enough to warrant conservation are termed 'exogeosites', and collectively comprise the Universe's 'exogeoheritage'. The "exo-" prefix expresses the extraterrestrial scope of exogeoconservation, and is preferable to "as- tro", which by analogy with the distinction between "astrobiology" and "exobiology" might be thought to encompass Earth-bound geoconservation as well (or else to relate somehow to stars). The "geo-" prefix is retained to preserve the link with "geoconservation", and because it refers commonly to any geosphere and not (despite its etymology) exclusively to the Earth.

\section{The value of exogeosites}

Exogeoconservation, in common with earthbound geoconservation, involves the attribution of various kinds of value to inanimate features, explored below. We need not discuss here whether such value (of whatever kind) is intrinsic or instrumental, i.e., whether these features are valuable strictly for their own sake or merely because they are useful or pleasing to conscious beings, a longstanding debate in environmental ethics (e.g. [12]). We do note, however, that lifeless extraterrestrial features are experienced so rarely, so remotely, and by so few people that protecting them for aesthetic, cultural or historical reasons may seem somewhat whimsical. In response, we would suggest that: (1) this situation is likely enough to change in coming centuries that minimising damage to these features is an imperative of intergenerational fairness; (2) there is a strong virtue-ethical imperative against destroying what one acknowledges to be valuable-in whatever way-even if it could not possibly be experienced by anybody else; see Routley's "last man" argument [13]; (3) the aesthetic, cultural and historic qualities of Antarctica are likewise accessible to very few people but protected by international treaty. The successes of the geoconservation movement on Earth demonstrate that scientific, cultural and aesthetic consideration can and should be accommodated within a single theoretical, practical and administrative approach to conservation [8-10].

\subsection{Scientific value}

There are many reasons why exogeosites may be scientifically valuable. They may, for example:

- serve as a representative reference "type" exemplifying a class, or be among very few known specimens of that class on a particular celestial body;

- be a particularly well studied feature for which key data are uniquely well constrained, and thus an important standard reference point even if not remarkable for any other reason;

- be an excellent resource for scientific education and training, perhaps by virtue of being well understood by experts but challenging to interpret for novices in the field;

be the subject of ongoing research of particular importance or significant controversy; 
- possess clear potential to drive future research once present technological limitations have been overcome, e.g., in the miniaturization of isotope mass spectrometers for Mars missions.

A great many geosites on Earth are protected because of their importance to scientific understanding and education. Under the UNESCO World Heritage Convention, sites may be recognised for preserving outstanding records of major events in earth's history or for exemplifying ongoing geological processes. One such recent (2016) addition to the World Heritage List is the Mistaken Point Ecological Reserve in Canada, site of the oldest known fossils of architecturally complex multicellular life, which is also protected as an Ecological Reserve by the Government of Newfoundland and Labrador.

Solar system exploration over the past 50 years has revealed numerous good candidates for exogeosite status on scientific grounds. The fluviolacustrine sedimentary record explored by the Curiosity rover in the central peak of Gale Crater is a clear contender for protection as a stratotype, both because it is the most extensively logged continuous stratigraphic section on Mars (so far about $100 \mathrm{~m}$ thick [14]) and because it reveals the presence, persistence, and evolution of a longstanding habitable lake close to the boundary of the Noachian and Hesperian periods. Among its various units are the only known extraterrestrial fluvial conglomerates [15], mudstones whose iron geochemistry reveals redox stratification in the paleolake [14], and laminated silica-rich rocks which may eventually prove to be an ideal hunting ground for microfossils [16].

A more remote example is provided by the high albedo areas in the centres of craters (most notably Occator Crater) on the dwarf planet Ceres. These "bright spots" are Ceres' most striking and unexpected features, and are currently understood as salt deposits precipitated by the evaporation of water mobilized from the interior of Ceres by heating and fracturing during impacts. The scientific value of these features consists in their being unique windows into the interior structure and geological history of dwarf planets, and the effects of large impacts upon them. It has been proposed that the water resources of Ceres could be used for the production of the hydrogen and oxygen for rocket fuel [17].

The scientific value of a site is strongly contingent on the state of exploration and understanding at any given time; several sites on the moon and Mars have great scientific value simply by dint of being among the first targets of in situ analysis by rovers or astronauts. Over time, the progress of science may diminish this value, while historic significance remains.

\subsection{Cultural and historic value}

Geosites and exogeosites may be recognised for historical contributions to the development of science, their significance in other historical events, or their meaning to a particular human community as embodied in art, literature, mythology or tradition, or experienced as a "sense of place". These qualities can be difficult to differentiate, perhaps especially in the context of outer space.

Many sites on Earth have been awarded geoconservation designations in whole or in part due to their role in the history of geological research. The NW Highlands Geopark in Scotland contains a number of formally recognised Sites of Special Scientific Interest and has also been designated a UNESCO Global Geopark. This region is protected not only for its spectacular scenery and important examples of regional lithologies, but because it hosts classic sections used by the British Geological Survey in the late 19th and early 20th centuries to develop our modern understanding of mountain building [18]. As the geological exploration of celestial bodies continues (most notably Mars), geosites associated with particular advances in scientific knowledge, or successful rover missions, should be similarly protected. The Viking 1 lander site on Mars provides a good example [2]; Viking 1 landed on Mars in 1976, producing the first photograph of the Martian surface successfully returned to Earth, and setting a record for the longest Martian surface mission that was not broken until 2010.

Various localities on Earth have been deemed subject to geoconservation for the cultural importance of their geology or geomorphology. Perhaps the paradigmatic example is Uluru-Kata Tjuta National Park in Australia, (formerly Ayers Rock-Mount Olga National Park). Uluru and Kata Tjuta are large red sandstone domes that have been designated a UNESCO World Heritage Site in recognition of the important roles they hold in the belief system of the local Aboriginal people. The primary example of a candidate exogeoheritage site of major cultural (as well as historical) importance is the landing site of the Apollo 11 mission [3]. Tranquility Base represents the site of the first successful manned mission to the lunar surface, the first sample-return mission to a celestial body, and the location of the first human footprints on another celestial body. It also hosts several pieces of scientific equipment, including the Passive Seismic Experiment Package and the Laser Ranging Retroreflector. NASA has requested that future crewed and robotic missions keep a distance of at least $75 \mathrm{~m}$ from the site [19].

Among non-planetary bodies, Halley's Comet is a pre-eminent candidate for culturally/historically motivated exogeosite status. It has been observed by many times in history, including by the ancient Chinese and Babylonian astronomers. In 1066, it appeared during the turmoil produced by the death of Edward the Confessor, King of England. The comet was hailed as an omen during the Norman Conquest that followed, and its image was famously embroidered in the Bayeux Tapestry alongside Edward's doomed heir Harold and the phrase isti mirant stella ("they marvel at the star"). Although it is not obviously threatened at present, we suggest that Halley's Comet is worthy of designation to facilitate its future protection.

\subsection{Aesthetic value}

The protection of aesthetic value is rightly encompassed within geoconservation. Beauty is sometimes dismissed as a matter of idiosyncratic subjective preference ("in the mind of the beholder") from which no publicly accessible, practicable criteria for conservation can be derived, and this has been thought to be a particular problem in debates about extraterrestrial environments, e.g., [20,21]. However, existing geoconservation practices suggest that such metaphysical worries are exaggerated, and do not actually prevent the identification and protection of sites of natural beauty. Examples include the Lake District in the United Kingdom, protected partly for aesthetic reasons as both a National Park and as a UNESCO World Heritage Site, and the South China Karst, another UNESCO World Heritage Site with additional provincial and municipal legal protection. The Antarctic Treaty, discussed below, explicitly protects the aesthetic qualities of a barren region whose scenic landscapes are dominated by rock and ice, like many planets, moons, etc. Indeed, our solar system abounds in uncontroversially beautiful features, from the rings of Saturn to the Valles Marineris canyon system of Mars. The number of such features will multiply as further exploration leads to a deepening aesthetic engagement with our planet's neighbourhood $[20,22]$.

\subsection{Ecological value}

Geological features on Earth have been conferred protection in recognition of the ecological value they provide. The island of Bass Rock in the Firth of Forth, Scotland, is formed of a Carboniferous trachyte volcanic plug, and is designated a Site of Special Scientific Interest for its large colony of seabirds (gannets). Extant life on celestial bodies, if it exists at all, is probably linked to particular geological phenomena or geomorphological features thereby deserving of special pro- 
tection. For example, any life on Mars or within the sub-ice oceans of the outer solar system is very likely to depend on geochemical energy resources requiring particular suites of minerals in contact with water (e.g., Fisk and Giovannoni, 1999 [23]; Gaidos et al., 1999 [24]). The discovery of extant extraterrestrial ecosystems will also necessitate exogeoconservation efforts to protect their fossil records, analogous to existing measures that protect exceptional archives of evolutionary history beyond Earth (e.g., the Burgess Shale of Canada, a UNESCO World Heritage Site currently protected by Parks Canada, and the Mistaken Point Ecological Reserve).

\section{Evolving threats to exogeoheritage}

Potential risks to exogeoheritage have been mounting steadily in recent decades. In 1959, the Russian Luna 2 probe became the first human object to reach another celestial object when it impacted the moon. The 1960s and 70s saw a rapid increase in the number of landings, intentional impacts, and accidental crashes on celestial bodies (Fig. 2), before a slowdown in the 1980s and early 90s. The beginning of the 21st century has seen a resurgence in space exploration, such that by the end of 2016, 79 human objects had landed, impacted, or crashed on celestial bodies. This number is likely to significantly increase in the coming decades as reinvigorated national space programs are joined by a new wave of spacefaring nations and enterprises.

Mars has been a particular focus of increasingly detailed and serious plans for human exploration and even settlement. NASA is legally mandated to prepare for a crewed Mars mission by 2033 [25], and has already invested tens of billions of dollars in the development of the Space Launch System, the most powerful rocket in history, as well as the Orion Crew Vehicle, both intended to reach Mars. Elon Musk's Space Exploration Technologies Corps (SpaceX) has announced plans for a mission to Mars by 2022, with crewed missions by 2024, which will include mining for water. SpaceX have also announced that the BFR launch system intended for martian missions may also be used to send humans to the moon. The renewal of interest in lunar missions has already prompted the creation of For All Moonkind, a non-profit organisation campaigning to protect the six human lunar landing sites (http:// forallmoonkind.org). Several companies have recently announced their intention to mine metals such as nickel, iron, and platinum from asteroids, including Planetary Resources, Deep Space Industries, and Kepler Energy and Space Engineering.
A significant minority of artificial objects sent to the surface of celestial objects have crashed, often at considerable distance from the intended landing site. Crashes have the potential to damage exogeosites, both physically and aesthetically. However, threats to exogeoheritage are perhaps more acute in respect of missions that land successfully. Threats are associated with surface transportation, resource removal, construction, scientific sampling and analysis, pollution, and waste disposal; all of these have been subject to geoconservation regulations on Earth. Exogeoconservation must also deal with problems specific to the extraterrestrial environment, such as landing site selection, explosive spacecraft malfunctions ("rapid unscheduled disassembly" in Musk's comic euphemism), and terraforming (which Musk has enthusiastically endorsed).

These considerations suggest that growing interest in space exploration and exploitation threaten the integrity of exogeoheritage. We suggest that agreement is needed now on measures to mitigate this risk without unduly retarding the progress of scientific, industrial, economic and cultural development off-world.

\section{Space law and exogeoconservation}

At present, the exploration and use of space is governed by the United Nations Treaties and Principles On Outer Space. The foundation of International Space Law is the Treaty on Principles Governing the Activities of States in the Exploration and Use of Outer Space, including the Moon and Other Celestial Bodies, also known as the UN Outer Space Treaty (OST). The OST has been ratified by all the major spacefaring nations and provides for an important principle in international law: that outer space cannot be appropriated by any one country. With regard to conservation, Article IX of the OST requires those exploring space, the moon, and other celestial bodies to "avoid their harmful contamination, and also adverse changes in the environment of the Earth resulting from the introduction of extraterrestrial matter".

A further advance in International Space Law relevant to the field of conservation was the Agreement Governing the Activities of States on the Moon and Other Celestial Bodies, also known as the Moon Treaty (MT). The MT is most specifically concerned with the ownership and exploitation of resources on the Moon [26], though its principles are applied to all celestial bodies. Article 7 of the MT states that those exploring the moon (and other celestial bodies) shall "take measures to prevent the disruption of the existing balance of its environment'. Further-

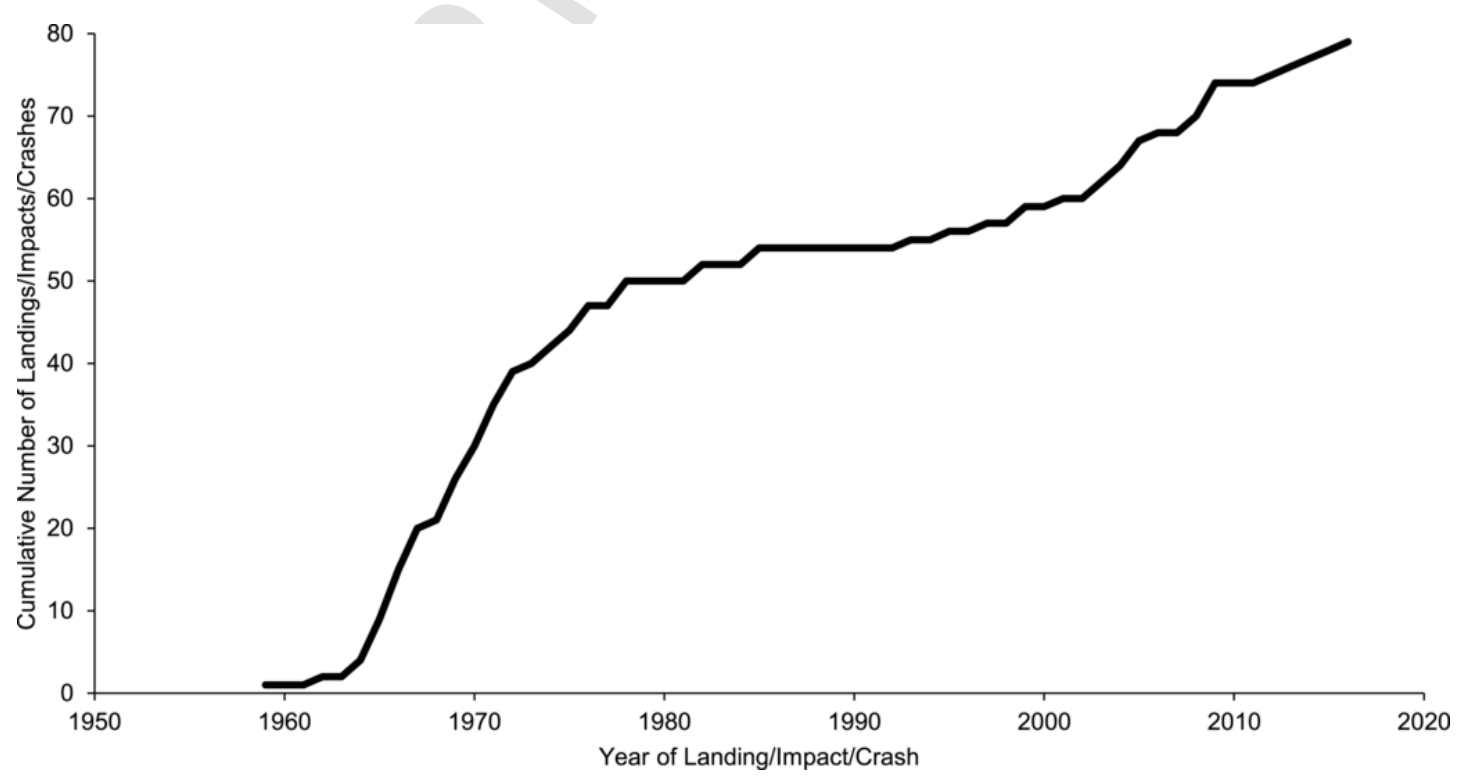

Fig. 2. Graph of cumulative number of landings, impacts, and crashes of human objects on celestial objects, 1959-2016 [33]. 
more, states are requested to report areas on the moon (and other celestial bodies) that are of "special scientific interest" so that they may be designated as "international scientific preserves for which special protective arrangements are to be agreed upon ...". It should be noted that the MT has largely been a failure, with none of the major spacefaring nations having ratified the Agreement, and therefore its principles have not been put into action.

International law has begun to address the potential for damage caused by spacecraft, but so far this is limited to damage to people, property, and other spacecraft. The Convention on International Liability for Damage Caused by Space Objects requires states launching spacecraft to be liable for damage caused by those launches and spacecraft to other nations. However, it makes no attempt to address damage caused to the natural environment, and is therefore of little assistance to the advancement of exogeoconservation.

The other major international agreement affording protection to exogeoheritage is the Partial Test Ban Treaty, known in full as the Treaty Banning Nuclear Weapon Tests in the Atmosphere, in Outer Space and Under Water. This treaty bans the triggering of nuclear explosions in outer space, and has been signed by the majority of nation states. China, France, and North Korea are notable exceptions with nuclear capabilities.

Scholarly articles discussing planetary protection and the development of space law have also been limited in their scope. Tennen [5] focused on the importance of quarantine, and the search for life, most notably the importance of not contaminating other celestial bodies. Issues around the 'degradation of the space environment' were considered by Williamson [6], focusing on space debris and intentional crashing of launched objects. Cockell and Horneck [2,27] propose a "planetary park" system for Mars, based on the National Parks found on Earth, but they do not differentiate between the many divergent management models covered by the generic term "National Park". They also note that their "planetary park" system would be somewhat similar to the UNESCO Geopark system in that it would prioritise geoconservation. This is the closest that debate has come to associating geoconservation with the processes and practice of extraterrestrial conservation.

Others have considered the need to protect certain landscapes in space, though this has mainly been through the lens of the exploitation of resources $[26,28]$. It is also in this context that Ehrenfreund et al. [29] set out the need for a new international treaty for the regulation of space exploration. The authors write in conclusion that “... scientific exploration activities are typically without major environmental impacts or conflicts among users ..." and that therefore celestial bodies have been governed up until now as de facto scientific preserves. However, scientific exploration and study can themselves threaten (exo)geosites-hence the common use of scientific research permits to control activities within protected sites.

The challenge of protecting celestial bodies is deepened by the widely accepted principle in international law that outer space is the province of all humankind, and cannot be claimed by any one state. On Earth, the vast majority of geoconservation legislation and governance is set at the level of nation state, or jurisdictions therein, whereas in outer space, the recognition of a common interest for all of humankind necessitates an international agreement on exogeoconservation. While two major international designations of geoheritage importance already exist (UNESCO World Heritage Sites and UNESCO Global Geoparks), these do not of themselves confer any additional protection on top of national/regional governmental provisions. Thus, these existing international designations are unsuitable for conferring primary protected status on celestial bodies.

Geoconservation management regimes tend to focus around the control of detrimental activities (e.g. the removal of geological mater- ial) and, to a greater or lesser extent, the access of individuals to a particular site. In considering the possibility of a future international agreement on exogeoconservation, we assume that the current widely accepted international space law, the OST, will not be amended. This is significant because Article I of the OST provides that there shall be "... free access to all areas of celestial bodies." This clause of the OST appears to be incompatible with placing restrictions on the access to exogeosites, and thus any future agreement would have to focus on the management of activities unless this Article is amended.

\section{The Antarctic Treaty System}

The Antarctic Treaty was initially signed by twelve countries in 1959 as an agreement for the peaceful international management of Antarctica. The original Treaty has been supplemented by subsequent agreements and protocols which are collectively referred to as the Antarctic Treaty System (ATS). As noted by Ehrenfreund et al. in their 2013 review [29] of international legal frameworks of interest to the development of Space Law, the ATS has been recognised as an example of best practice for international cooperation on environmental issues. Through Antarctic Treaty Consultative Meetings (ATCM), areas within Antarctica of special historic or scientific interest, including geosites, can receive conservation designations, the protection of which is then delegated to the individual member states that may operate in the designated area. Antarctic Specially Protected Areas (ASPAs) are the usual protective designation for geosites, and a permit from one of the Parties to the Treaty is required for entry. Antarctic Specially Managed Areas (ASMAs) are used for the designation of historic monuments and areas of mutual interference. Permits are not required, however the ATCM agrees a code of conduct for activities within each ASMA.

As mentioned above, a permit model is not thought to be compatible with the OST, and therefore the ASPA model would not be applicable. Of more interest is the model of ASMAs, where sites are designated through international agreement, and while access as a right is maintained, a code of conduct controls what may occur within that area. This has the additional benefit of putting to one side the issue of extraction and ownership of resources as a principle across all celestial bodies one of the main reasons the MT has failed to be ratified by the spacefaring nations. Rather, a model based on ASMAs would only control activities within specific, spatially defined, geosites.

\section{An international agreement on exogeoconservation}

Based on the success of the ATS, and the recognised system of ASMA designations, it is proposed that a future international agreement on exogeoconservation should focus on the identification and recognition of specific exogeosites where all ratifying parties can agree special protection is needed, rather than blanket controls on activity across all celestial bodies, as in the failed MT. These Exogeoheritage Management Sites (EMSs) could be developed in a supplementary agreement to the OST, similar to the Environment Protocols to the ATS. This agreement would need to include the setting up of an international committee, here called the Exogeoheritage Consultative Meeting (ECM), which would agree to the designation of EMSs, and the code of practice for each EMSs. Each code of conduct, building on the codes used for ASMAs, may include discussion of:

1. Access and movement within the EMS, including landings

2. Activities that may be conducted

3. Installation of structures

4. The collection or, removal of, or harmful interference with anything not brought into the area

5. The disposal of waste, including propellant exhausts

6. The introduction of materials, both abiotic and biotic 


\section{Requirements for appropriate reporting}

8. Requirements for redress, remediation, and restoration

Involvement in the processes of the ATCM requires a State to be active in Antarctic research. Unlike the ATCM, and in recognition of previous international statements on the common ownership of outer space, it is envisaged that the ECM would be representative of all nations (like UNESCO and its processes to designate World Heritage Sites), not only those currently practicing spaceflight. A further advantage of EMSs is that they are applicable for use on all areas of outer space and celestial bodies, and can be used in all areas of conservation, not just exogeoconservation, such that were extraterrestrial life ever to be found, an international framework for its protection would already be in place. The disadvantage of the EMS system is that it only establishes a code of practice, not a legal instrument, and compliance therefore requires a certain amount of goodwill from the State parties and entities involved. It also defers the difficult yet important wider debate on the efficacy of resource extraction on celestial bodies, by focusing on protecting the most important sites rather than blanket controls on potentially destructive activities. Indeed, it may be an advantage of the proposed approach that it avoids premature overregulation.

Restricting access to the most important geosites is a recognised geoconservation management technique on Earth and therefore ideally the OST would be amended to allow for the prohibition of entry without a permit into what might be called Exogeoheritage Protected Sites (EPSs), in a similar manner to ASPAs in Antarctica.

\section{Conclusion}

Geological heritage in our solar system is increasingly threatened by the expansion of human activities in space, including scientific, industrial and tourism-related endeavours. While previous work has enumerated these threats and offered a number of possible mitigation strategies, there has been a lack of attention in the space policy community to the existing practices of geoconservation on Earth, which provide a ready-made theoretical and practical toolkit ideally suited for application to the lifeless but valuable heritage of celestial bodies. The development of terrestrial geoconservation over the past century has laid the legal/administrative and practical foundations necessary for the new task of "exogeoconservation", which should be advanced by means of international treaty arrangements similar to those that protect Antarctica.

\section{Acknowledgements}

JJM is funded by Mitacs and the Government of Newfoundland and Labrador, Department of Fisheries and Land Resources. SM is funded by the European Union's Horizon 2020 Research and Innovation Programme under the Marie Sklodowska-Curie grant agreement 747877. We gratefully acknowledge the bibliographic support of D. Marosi and the comments of C. S. Cockell. This paper was improved by the constructive and helpful comments of two anonymous reviewers.

\section{Appendix A. Supplementary data}

Supplementary data related to this article can be found at https:// doi.org/10.1016/j.actaastro.2018.05.034.

\section{References}

[1] M. Williamson, Space ethics and protection of the space environment, Space Pol. 19 (2003) 47-52.
[2] C.S. Cockell, G. Horneck, A planetary park system for Mars, Space Pol. 20 (2004) 291-295.

[3] G. Fewer, Conserving space heritage: the case of tranquility base, J. Brit, Interplanetary Soc. 60 (2007) 3-8.

[4] J.S.P. Walsh, Protection of humanity's cultural and historic heritage in space, Space Pol. 28 (2012) 234-243.

[5] L.I. Tennen, Evolution of the planetary protection policy: conflict of science and jurisprudence?, Adv. Space Res. 34 (2004), 354-2362.

[6] M. Williamson, Protection of the space environment: the first small steps, Adv. Space Res. 34 (2004) 2338-2343.

[7] I. Alvár, A. Horváth, Do we need "environmental protection" in the solar system?, in: G.W. Heath (Ed.), Space Safety and Rescue American Astronautical Society, San Diego, 1990, pp. 393-398.

[8] C.D. Prosser, Our rich and varied geoconservation portfolio: the foundation for the future, PGA (Proc. Geol. Assoc.) 124 (2013) 568-580.

[9] M. Brock, V. Semeniuk, Geoheritage and geoconservation - history, definition, scope and scale, J. Roy. Soc. West Aust. 90 (2007) 53-87.

[10] M. Gray, Geodiversity: Valuing and Conserving Abiotic Nature, second ed., Wiley-Blackwell, Chichester, 2013.

[11] A. Salvador, International Stratigraphic Guide: a Guide to Stratigraphic Classification, Terminology, and Procedure, fourth ed., Geological Society of America, Boulder, Colorado, 1994.

[12] J.S.J. Schwartz, T. Milligan, Introduction: the scope and content of space ethics, in: J. Schwartz, T. Milligan (Eds.), The Ethics of Space Exploration, Space and Society, Springer, Cham, 2016.

[13] R. Routley, Is there a need for a new, an environmental ethic, In: Proceedings of the XVth World Congress of Philosophy, vol. 1, 1973, pp. 205-210.

[14] J.A. Hurowitz, J.P. Grotzinger, W.W. Fischer, S.M. McLennan, R.E. Milliken, N. Stein, A.R. Vasavada, D.F. Blake, E. Dehouck, J.L. Eigenbrode, A.G. Fairén, Redox stratification of an ancient lake in Gale crater, Mars, Science 356 (2017), p.eaah6849.

[15] R.M. Williams, J.P. Grotzinger, W.E. Dietrich, S. Gupta, D.Y. Sumner, R.C. Wiens, N. Mangold, M.C. Malin, K.S. Edgett, S. Maurice, O. Forni, Martian fluvial conglomerates at Gale crater, Science 340 (2013) 1068-1072.

[16] R.V. Morris, D.T. Vaniman, D.F. Blake, R. Gellert, S.J. Chipera, E.B. Rampe, D.W Ming, S.M. Morrison, R.T. Downs, A.H. Treiman, A.S. Yen, Silicic volcanism on Mars evidenced by tridymite in high-SiO2 sedimentary rock at Gale crater, In: Proceedings of the National Academy of Sciences, vol.113, 2016, pp. 7071-7076.

[17] B.A. Palaszewski, Solar system exploration augmented by lunar and outer planet resource utilization: historical perspectives and future possibilities, In: 7th Symposium on Space Resource Utilization, 2014.

[18] B.N. Peach, J. Horne, W. Gunn, C.T. Clough, J.J.H. Teall, L.W. Hinxman, The geological structure of the north-west Highlands of Scotland, HM Stationery Office (1907).

[19] Chang, 2012: http://www.nytimes.com/2012/01/10/science/space/ a-push-for-historic-preservation-on-the-moon.html.

[20] R. Sparrow, The ethics of terraforming, Environ. Ethics 21 (1999) 227-245.

[21] J.S. Schwartz, On the moral permissibility of terraforming, Ethics Environ. 18 (2013) 1-31.

[22] S. McMahon, The aesthetic objection to terraforming Mars, in: J.S.J. Schwartz, T. Milligan (Eds.), The Ethics of Space Exploration, Springer, London, 2016.

[23] M.R. Fisk, S.J. Giovannoni, Sources of nutrients and energy for a deep biosphere on Mars, J. Geophys. Res.: Plan 104 (1999) 11805-11815.

[24] E.J. Gaidos, K.H. Nealson, J.L. Kirschvink, Life in ice-covered oceans, Science 284 (1999) 1631-1633.

[25] NASA Transition Authorization Act, 2017, 2017 https://www.congress.gov/bill/ 115th-congress/senate-bill/442/text, Accessed 29 December 2017.

[26] N.L. Griffin, Americans and the moon treaty, J. Air Law Commer. 46 (1981) 729.

[27] C.S. Cockell, G. Horneck, Planetary parks-formulating a wilderness policy for planetary bodies, Space Pol. 22 (2006) 256-261.

[28] I. Almar, What could COSPAR do to protect the planetary and space environment?, Adv. Space Res. 30 (2002) 1577-1581.

[29] P. Ehrenfreund, M. Race, D. Labdon, Responsible space exploration and use: balancing stakeholder interests, N. Space 1 (2013) 60-72.

[30] R.H. Whittaker, Communities and Ecosystems, second ed., Macmillian, London, 1975.

[31] M.W. Busch, J.D. Giorgini, S.J. Ostro, L.A.M. Benner, R.F. Jurgens, R. Rose, M.D. Hicks, P. Pravec, P. Kusnirak, M.J. Ireland, D.J. Scheeres, S.B. Broschart, C. Magri, M.C. Nolan, A.A. Hine, J.L. Margot, Physical modeling of near-Earth Asteroid (29075) 1950 DA, Icarus 190 (2007) 608-621.

[32] M.H. Carr, J.W. Head, Martian surface/near-surface water inventory: sources, sinks, and changes with time, Geophys. Res. Lett. 42 (2015) 726-732.

[33] NASA Space Science Data Coordinated Archive. https://nssdc.gsfc.nasa.gov/.

Dr. Jack J. Matthews is a Postdoctoral Researcher at Memorial University of Newfoundland, and a Research Fellow at the Oxford University Museum of Natural History

Dr. Sean McMahon is a Research Fellow at the UK Centre for Astrobiology at the University of Edinburgh 